\title{
Assessing habitat-related disturbance in bird communities: Applying hemeroby and generalism as indicators
}

\author{
C. Battisti1,6, G. Fanelli², D. Pavel ${ }^{3}$, L. Redolfi De Zan ${ }^{4,5}$, S. Rossi de Gasperis 3 \\ and G. Caneva ${ }^{3}$
}

\author{
1 "Torre Flavia” LTER (Long Term Ecological Research) Station, Servizio Aree protette, Città metropolitana \\ di Roma Capitale, via Tiburtina, 691, 00159 Rome, Italy \\ ${ }^{2}$ Laboratorio di Agrobiologia, Dipartimento di Biologia, Seconda Università di Roma Tor Vergata, \\ via della Ricerca Scientifica, 00133 Rome, Italy \\ ${ }^{3}$ Dipartimento di Scienze, Università degli Studi Roma Tre, Viale Marconi, 446, 00146 Rome, Italy \\ ${ }^{4}$ Consiglio per la ricerca in agricoltura e l'analisi dell'economia agraria, Centro di Ricerca per l'Agrobiologia \\ e la Pedologia (CREA-ABP), Via di Lanciola 12/a, 50125 Cascine del Riccio, Firenze, Italy \\ ${ }^{5}$ Centro Nazionale per lo Studio e la Conservazione della Biodiversità Forestale 'Bosco Fontana'. Carabinieri. \\ Strada Mantova 29, 46045 Marmirolo (MN), Italy \\ ${ }^{6}$ Corresponding author.E-mail: c.battisti@cittametropolitanaroma.gov.it
}

Keywords: Habitat-related communities, Hemeroby score, Hemerobiotic diversity score, Hump-shaped pattern, Intermediate generalism hypothesis.

\begin{abstract}
We tested the application of the concept of hemeroby and generalism at community level, on a set of birds occurring in various habitats of central Italy characterized by different level of disturbance. In each habitat-related bird community, we applied the recently published species-specific score in hemeroby (a proxy of habitat-related disturbance; $\mathrm{HS}_{\mathrm{i}}$ ) and hemerobiotic diversity (a proxy of generalism; $\mathrm{H}^{\prime} \mathrm{H}_{\mathrm{i}}$ ) to local species frequency, obtaining weighted values at community level $\left(\mathrm{HS}_{\text {tot }}\right.$ and $\mathrm{H}^{\prime} \mathrm{H}_{\text {tot }}$ ). The relationship between $\mathrm{HS}_{\text {tot }}$ vs. $\mathrm{H}^{\prime} \mathrm{H}_{\text {tot }}$ showed an increasing trend moving from reed beds through forests and mosaics to urban communities. Quadratic model (best fit) evidenced a significant correlation between these variables and a tendency toward a hump-shaped curve, corroborating results already observed at species level (intermediate generalism hypothesis). The co-inertia analysis discriminated four groups of habitat-related communities, characterized by species with different levels of disturbance-sensitivity (expressed by $\mathrm{HS}_{\mathrm{i}}$ ) and generalism (expressed by hemerobiotic diversity; $\mathrm{H}^{\prime} \mathrm{H}_{\mathrm{i}}$ ): (i) forest type-related, where mature wood communities were separated from a coppiced wood one; (ii) communities of moderately disturbed agricultural habitats; (iii) communities embedded in highly disturbed mosaics, and (iv) a group including either a highly disturbed urban habitat or a low disturbed wetland reed bed, with highly specialized species (respectively, synanthropic species and water-related species). Total scores in hemeroby and hemerobiotic diversity, expressing the composition in species with different disturbance preference and generalism, might act as good community-based indicators of degree of naturalness, especially for forest habitat types.
\end{abstract}

Nomenclature: Clements (2000).

Abbreviations: CoIA - Co-Inertia Analysis, HS - Hemeroby Score, HH - Hemerobiotic diversity, PCA - Principal Components Analysis.

\section{Introduction}

Biological species show different levels of preference and sensitivity to differently disturbed habitat types, depending on their natural history, ecology, behaviour and life-cycle (Sousa 1984, Dornelas 2010). In this regard, ecologists have investigated the role of disturbances at level of the structure of populations, for example considering species-specific ecological traits (Henle et al. 2004, Ewers and Didham 2006). In particular, a few of these traits are considered to be strong predictors of sensitivity to natural or anthropogenic perturbations (Mouillot et al. 2013): for example, the level of generalism has been considered an important ecological trait that has a role of predictor in disturbance sensitivity of species (Julliard et al. 2006, Katayama et al. 2014). In fact, stenoecious species show different responses to natural or anthropogenic perturbations when compared to progressively more generalist species (Wiens 1989, Reif et al. 2013, Battisti et al. 2016, for a review).

Among the many biological indicators which have been proposed for the study of disturbances, a paramount importance is represented by the indicator of hemeroby, used in the assessment of the level of disturbance in different vegetation types and defined as the sum of the effects of disturbances on ecological components (ter Braak and Barendregt 1986, Kowarik 1988, Grabherr et al. 1998, Steinhardt et al. 1999, 
Table 1. Habitat-related avian communities (with code) utilized in this study and related references.

\begin{tabular}{|c|c|c|}
\hline Habitat type & code & Reference \\
\hline Urban settlements & Urb & Taffon and Battisti 2005 \\
\hline $\begin{array}{l}\text { Crop-lands (embedded in a low anthropized landscape } \\
\text { matrix) }\end{array}$ & $\mathrm{Cr} 1$ & Taffon and Battisti 2005 \\
\hline Olive groves & Oli & Taffon and Battisti 2005 \\
\hline Mosaics (with a crop land matrix) & Mo1 & Taffon and Battisti, 2005 \\
\hline Mosaics (with olive groves as a matrix) & $\mathrm{Mo} 2$ & Taffon and Battisti 2005 \\
\hline Crop-lands (embedded in a suburban landscape matrix) & $\mathrm{Cr} 2$ & Malavasi et al. 2009 \\
\hline Mosaics (with urbanized matrix) & Mo3 & Malavasi et al. 2009 \\
\hline $\begin{array}{l}\text { Phragmites reed beds (embedded in a coastal wetland } \\
\text { protected area) }\end{array}$ & Ree & Malavasi et al. 2009 \\
\hline Forest habitats (beechwoods) & Fo1 & Vuerich et al. 2006 \\
\hline Forest habitats (mature Mediterranean oakwoods) & Fo2 & Battisti and Fanelli 2011 \\
\hline Forest habitats (coppiced Mediterranean oakwoods) & Fo3 & Battisti and Fanelli 2011 \\
\hline $\begin{array}{l}\text { Forest habitats (urban park with mature Mediterranean } \\
\text { oak- woods and pinewoods) }\end{array}$ & Fo4 & Battisti and Capecchi 2015 \\
\hline
\end{tabular}

Hill et al. 2002, Testi et al. 2009, Schleupner and Schenider 2013). Hemeroby can be easily calculated by analysing the composition of species in assemblages belonging to specific habitat types (Fanelli et al. 2005). As plant species can be considered indicators of anthropogenic pressures and impacts (Bossel 1999), plant communities are even better suited for the evaluation of hemeroby than single species, since a combination of species carries a larger amount of information than a single one. Then, plant community can be used to show the score of hemeroby of a habitat (Fanelli et al. 2005), and these values are given in a 10-point scale (from completely pristine habitats to completely altered vegetation-based habitat types) proposed by Kowarik (1988).

Although hemeroby was originally developed in the context of plant ecology, the concept can be applied also to other organisms. Among vertebrates, birds are a species-rich class characterized by species with different ranges and habitats where they occur along a gradient of increasing disturbance: from species related to old forests and other pristine habitats (e.g., interior species; Villard 1998), to species related to crops and extensive agriculture (e.g., farmland species, edge species; Gregory et al. 2004) to synanthropic ones living in urbanized contexts (Marzluff et al. 2001, Blair 2004, Crooks et al. 2004). The great availability of information about the breeding ecology of birds at multiple scales (Sharrock 1976, Lack 1986, Devictor et al. 2008a, Devictor and Robert 2009, Belmaker et al. 2012, Morelli et al. 2016), allows their characterization from disturbance-sensitivity species to disturbance-tolerant ones following their occurrence along a gradient from pristine habitats to highly disturbed ecosystems (Brawn et al. 2001). In particular, the sensitivity to disturbance of birds can be expressed indirectly from the relationship between species and habitat where they occur (Brawn et al. 2001, Fanelli and Battisti 2014), and recently it was possible to assess the level of hemeroby of a large number of bird species for Central Italy (Battisti and Fanelli 2015a).

In this paper, we would extend the application of the concept of hemeroby and generalism at community level, testing for the first time the effectiveness of this approach on a set of avian assemblages occurring in habitat types characterized by different levels of disturbance (from wetland reed beds through semi-natural forests to urban habitats). To strengthen the resulting values, we would also test their assessment at community level using dataset that are independent from those used for developing the scores of hemeroby and generalism indices at species level (Battisti and Fanelli 2015a). Moreover, considering that the relationship between hemeroby of the species and their generalism shows a hump-shaped pattern (intermediate generalism hypothesis; Battisti and Fanelli 2015a), we would test its occurrence also at community level.

\section{Materials and methods}

We analyzed a sample of 12 original studies on breeding bird communities located in Latium (Tyrrhenian central Italy) and carried out using a comparable sampling protocol (point counts method; Bibby et al. 2000) (Table 1). The original studies were selected to obtain a heterogeneous sample of bird communities occurring in vegetation-related habitat types along a gradient with a different level of disturbance: from wetland reed beds to coppiced and mature forests, to agricultural and urban habitat types.

Each of the 12 studies has been carried out using a different number of sampling stations; among them Ree and Fo3 habitat types have only 10 point counts, therefore we built a new dataset by randomly selecting 10 point counts for each 
Table 2. Values of $\mathrm{HS}_{\mathrm{i}}$ and $\mathrm{H}^{\prime} \mathrm{H}_{\mathrm{i}}$ for the 54 breeding bird species (from Battisti and Fanelli 2015a) sampled in the 12 habitat types investigated for this study, in which they occurred. For habitat type abbreviations, see Table 1.

\begin{tabular}{|c|c|c|c|}
\hline Species & $\mathrm{HS}_{\mathrm{i}}$ & $\mathrm{H}^{\prime} \mathrm{H}_{\mathrm{i}}$ & Habitat-related bird communities \\
\hline Accipiter nisus & 1 & 0 & Fo2 \\
\hline Aegithalos caudatus & 1.51 & 0.884 & $\mathrm{Cr} 1 \mathrm{Oli} \mathrm{Mo} 1 \mathrm{Mo} 2 \mathrm{Fo} 1 \mathrm{Fo} 2 \mathrm{Fo} 3 \mathrm{Fo} 4$ \\
\hline Alauda arvensis & 2.774 & 0.535 & Cr1 Oli Mo1 \\
\hline Apus apus & 3.951 & 1.063 & Urb Cr1 Oli Mo1 Mo2 Fo3 Fo4 \\
\hline Buteo buteo & 1.16 & 0.279 & Fo3 \\
\hline Carduelis carduelis & 3.038 & 1.415 & Urb Cr1 Oli Mo1 Mo2 Cr2 Mo3 Ree Fo2 Fo3 \\
\hline Carduelis chloris & 2.876 & 1.475 & Urb Cr1 Oli Mo1 Mo2 Fo2 Fo4 \\
\hline Certhia brachydactyla & 1.41 & 0.549 & Cr1 Oli Mo2 Fo2 Fo3 Fo4 \\
\hline Cettia cetti & 2.806 & 0.319 & Urb Cr1 Oli Mo1 Mo2 Cr2 Ree \\
\hline Cisticola juncidis & 2.703 & 0.608 & Cr2 Mo3 Ree \\
\hline Columba livia & 4.25 & 0.546 & Urb Cr1 Oli Mo1 Mo2 Cr2 Mo3 Fo3 \\
\hline Corvus cornix & 2.378 & 1.249 & Urb Cr1 Oli Mo1 Mo2 Cr2 Mo3 Fo1 Fo2 Fo3 Fo4 \\
\hline Corvus monedula & 4.348 & 0.631 & Urb Oli Mo2 \\
\hline Coturnix coturnix & 2.602 & 0.672 & Fo2 \\
\hline Cuculus canorus & 1.36 & 0.697 & Cr1 Oli Fo1 Fo3 \\
\hline Cyanistes caeruleus & 1.962 & 1.094 & Fo4 \\
\hline Delichon urbicum & 4.45 & 0.696 & Urb Cr1 Oli Mo1 Mo2 \\
\hline Dendrocopos major & 1.192 & 0.317 & Fo2 Fo3 \\
\hline Emberiza cirlus & 2.296 & 1.013 & Urb Cr1 Oli Mo1 Mo2 Fo2 Fo3 \\
\hline Erithacus rubecula & 1.362 & 0.694 & Urb Cr1 Oli Mo1 Mo2 Fo1 Fo2 \\
\hline Falco subbuteo & 1.895 & 0.688 & Fo4 \\
\hline Falco tinnunculus & 2.455 & 1.142 & Cr1 Oli Mo1 Fo4 \\
\hline Fringilla coelebs & 1.443 & 0.782 & Urb Cr1 Oli Mo1 Mo2 Fo1 Fo4 \\
\hline Gallinula chloropus & 3 & 0 & Urb Cr2 Mo3 Ree \\
\hline Garrulus glandarius & 1.227 & 0.529 & Mo3 \\
\hline Hirundo rustica & 3.689 & 1.026 & Urb Cr1 Oli Mo1 Mo2 Fo3 Fo4 \\
\hline Jynx torquilla & 2.178 & 0.89 & Oli Mo1 Mo2 Fo3 \\
\hline Lanius collurio & 2.243 & 0.917 & Mo1 \\
\hline Luscinia megarhynchos & 1.838 & 0.998 & Urb Cr1 Oli Mo1 Mo2 Fo2 Fo3 \\
\hline Merops apiaster & 2.707 & 0.496 & Cr1 Oli \\
\hline Motacilla alba & 3.582 & 1.119 & Urb Cr1 Oli Mo1 Mo2 Cr2 Mo3 Fo1 Fo4 \\
\hline Motacilla cinerea & 3.018 & 0.451 & Fo1 \\
\hline Muscicapa striata & 2.842 & 1.556 & Fo4 \\
\hline Oriolus oriolus & 1.269 & 0.587 & Fo3 \\
\hline Parus major & 2.108 & 1.268 & Urb Cr1 Oli Mo1 Mo2 Fo1 Fo2 Fo3 Fo4 \\
\hline Passer domesticus & 4.084 & 0.899 & Fo4 \\
\hline Passer montanus & 4.226 & 0.667 & Urb Cr1 Oli Mo1 Mo2 Cr2 Mo3 \\
\hline Phasianus colchicus & 2.548 & 0.858 & Cr1 Oli \\
\hline Phylloscopus collybita & 1.058 & 0.222 & Urb Cr1 Oli Mo1 Mo2 Fo1 Fo2 Fo3 \\
\hline Pica pica & 2.87 & 1.4 & Oli Cr2 Mo3 Ree Fo3 \\
\hline Picus viridis & 1.295 & 0.592 & Fo1 Fo2 Fo3 \\
\hline Regulus ignicapilla & 1.683 & 0.782 & Cr1 Oli Fo3 Fo4 \\
\hline Saxicola torquatus & 2.649 & 0.648 & Urb Cr1 Oli Mo1 Mo2 Cr2 Mo3 Ree \\
\hline Serinus serinus & 2.934 & 1.456 & Urb Cr1 Oli Mo1 Mo2 Cr2 Fo2 Fo3 Fo4 \\
\hline Sitta europaea & 1 & 0 & Fo2 Fo4 \\
\hline Streptopelia decaocto & 4.526 & 0.848 & Urb Cr1 Oli Mo1 Mo2 Cr2 Fo3 Fo4 \\
\hline Streptopelia turtur & 1.674 & 0.896 & Cr1 Oli Mo1 Mo2 Fo2 Fo3 \\
\hline Sturnus vulgaris & 3.656 & 1.158 & Urb Cr1 Oli Mo2 Cr2 Mo3 Fo2 Fo4 \\
\hline Sylvia atricapilla & 1.99 & 1.298 & Urb Cr1 Oli Mo1 Mo2 Fo1 Fo2 Fo3 Fo4 \\
\hline Sylvia cantillans & 1.863 & 0.98 & Fo2 \\
\hline Sylvia melanocephala & 2.3 & 1.118 & Urb Cr1 Oli Mo1 Mo2 Fo2 Fo4 \\
\hline Troglodytes troglodytes & 1.826 & 1.129 & Urb Cr1 Oli Mo1 Mo2 Fo1 Fo2 Fo3 Fo4 \\
\hline Turdus merula & 2.129 & 1.35 & Urb Cr1 Oli Mo1 Mo2 Cr2 Mo3 Fo1 Fo2 Fo3 Fo4 \\
\hline Upupa ерорs & 2.337 & 1.169 & Cr1 Oli Mo1 \\
\hline
\end{tabular}

of the remaining ten habitat types ("sample" function in $\mathrm{R}$ package "base"). In order to have a representative random dataset for each habitat type, we compared the similarity/dissimilarity between 20 random matrices (i.e., each one made of 10 point counts randomly selected) for each habitat type by calculating an index of similarity " $R$ " obtained from a permutation test (n. perm $=999$, distance of similarity between ma- trices = euclidean; "anosim" function in R package "vegan"). The $R$ value is based on the difference of mean ranks between matrices and within matrices and it ranges between -1 and +1 ; values close to 1 indicate significant dissimilarity (p-value $<$ 0.05). Being all matrices not significantly different for each habitat type (see Results), we were able to use the new dataset for the analyses. On this new dataset, for each species in each 
bird community we re-calculated their relative frequency as $\mathrm{fr}_{\mathrm{i}}=\mathrm{n}$. individuals of the species $\mathrm{i}_{\mathrm{th}} /$ total $\mathrm{n}$. of sampled individuals (Supplementary materials S1).

We calculated the hemeroby value for each species considering the geographically-related datasets (e.g., bird atlases) which report the quantitative distribution of habitat preference for a large number of species, and referring each habitat type to a level of hemeroby on the base of the scale of Kowarik (1988).

For each bird species we obtained a hemeroby score (hereafter $\mathrm{HS}_{\mathrm{i}}$ ) calculated as:

$\mathrm{HS}_{\mathrm{i}}=\sum_{\mathrm{j}} \mathrm{F}_{\mathrm{ij}} \times \mathrm{H}_{\mathrm{j}} / \sum_{\mathrm{j}} \mathrm{F}_{\mathrm{ij}}$,

where $F_{i j}$ is the frequency of occurrence of the bird species $i$ in the habitat $\mathrm{j}$ and $\mathrm{H}_{\mathrm{j}}$ is the hemeroby of the $\mathrm{j}^{\text {th }}$ habitat (obtained from Kowarik 1988); the $\mathrm{j}$ subscripts refer to summation over habitats. This formula is widely used in plant ecology, and represents the weighted average or barycentre of the species distribution along the hemerobiotic gradient. With the increase of $\mathrm{HS}_{\mathrm{i}}$, the species connection to progressively more disturbed habitats also increases.

Analogously, we measured the generalism for each species from frequency of occurrence among different habitat types (hemerobiotic diversity) by means of Shannon's formula:

$\mathrm{H}^{\prime} \mathrm{H}_{\mathrm{i}}=-\Sigma \mathrm{H}_{\mathrm{ik}} \times \ln \mathrm{H}_{\mathrm{ik}}$.

where $\mathrm{H}_{\mathrm{ik}}=\mathrm{F}_{\mathrm{ik}} \times \mathrm{HS}_{\mathrm{i}} / \sum_{\mathrm{j}} \mathrm{F}_{\mathrm{ik}}$, ( $\mathrm{F}_{\mathrm{ik}}$ is the frequency of occurrence of the bird species $i$ at a level of hemeroby $k$ ). This score may indicate the level of generalism/specialization of the species $i$ in regard to the frequency of different disturbed (hemerobiotic) habitat types (higher $\mathrm{H}^{\prime} \mathrm{H}_{\mathrm{i}}$ expressing a higher generalism of the species; further details in Battisti and Fanelli 2015a, Fanelli and Battisti 2015).

Then, we also calculated the species-specific frequency considering that (i) each $\mathrm{i}_{\text {th }}$ species has a proper score both in hemeroby (a proxy of habitat-related disturbance; $\mathrm{HS}_{\mathrm{i}}$ ) and hemerobiotic diversity (a proxy of habitat generalism; $\mathrm{H}^{\prime} \mathrm{H}_{\mathrm{i}}$ ) and that (ii) for each habitat, it is possible obtain a weighted value for these two indices for each species in each community, multiplying their frequency for the species-specific index score (see Supplementary materials S1 and S2). These regional data were recently calculated (Battisti and Fanelli 2015a), and they are here newly reported in Table 2 .

Then, we obtained the sum of species-specific index scores named, respectively, total hemeroby score (a proxy of habitat-related disturbance expressed at community level):

$\mathrm{HS}_{\text {tot }}=\Sigma \mathrm{fr}_{\mathrm{i}} \times \mathrm{HS}_{\mathrm{i}}$

and total hemerobiotic diversity (a proxy of generalism at community level):

$\mathrm{H}^{\prime} \mathrm{H}_{\mathrm{tot}}=\Sigma \mathrm{fr}_{\mathrm{i}} \times \mathrm{H}^{\prime} \mathrm{H}_{\mathrm{i}}$,

where (i) $\mathrm{fr}_{\mathrm{i}}$ is the relative frequency of each $\mathrm{i}_{\mathrm{th}}$ species and (ii) $\mathrm{HS}_{\mathrm{i}}$ and $\mathrm{H}^{\prime} \mathrm{H}_{\mathrm{i}}$ correspond, respectively, to the scores in hemeroby and hemerobiotic diversity of each $i_{\text {th }}$ species in each community. We calculated confidence intervals ( $^{\text {th }}$ and $95^{\text {th }}$ percentile) for $\mathrm{HS}_{\text {tot }}$ and $\mathrm{H}^{\prime} \mathrm{H}_{\text {tot }}$ by selecting at random $\mathrm{N}-1$ species, calculating the averaged values and repeating
Table 3. Results of the similarity/dissimilarity test performed on 20 matrices randomly generated for each of the 10 habitat types: $\mathrm{N}_{\mathrm{s}}$ is the total number of species, $\mathrm{N}$ is the total number of point counts (as recorded in original papers, see Table 1) from which we randomly selected the 10 points to build the 20 matrices; the $\mathrm{R}$ index and $\mathrm{p}$-value are obtained from the test. The habitat types Ree $(\mathrm{Ns}=12, \mathrm{~N}=10)$ and Fo3 $(\mathrm{Ns}=38, \mathrm{~N}=10)$ were excluded from this analysis (see Materials and methods, for details).

\begin{tabular}{ccccc}
\hline $\begin{array}{c}\text { Habitat } \\
\text { type }\end{array}$ & $\mathrm{N}_{\mathrm{s}}$ & $\mathrm{N}$ & $\mathrm{R}$ & $\mathrm{p}$-value \\
\hline Urb & 32 & 14 & -0.067 & 1 \\
Cr1 & 46 & 30 & -0.027 & 0.96 \\
Oli & 46 & 37 & -0.037 & 1 \\
Mo1 & 41 & 27 & -0.043 & 1 \\
Mo2 & 32 & 13 & -0.077 & 1 \\
Cr2 & 19 & 12 & -0.088 & 1 \\
Mo3 & 18 & 13 & -0.074 & 1 \\
Fo1 & 69 & 14 & -0.075 & 1 \\
Fo2 & 38 & 17 & -0.054 & 1 \\
Fo4 & 33 & 47 & -0.031 & 0.97 \\
\hline
\end{tabular}

the process with 100 permutations. Habitat-related communities, characterized by their scores of $\mathrm{HS}_{\text {tot }}$ and $\mathrm{H}^{\prime} \mathrm{H}_{\text {tot }}$, have been plotted in a Cartesian space to detect a pattern along the two gradients (from low to high hemeroby and from low to high hemerobiotic diversity). To test the hypothesis that the $\mathrm{HS}_{\text {tot }}$ and $\mathrm{H}^{\prime} \mathrm{H}_{\text {tot }}$ are directly correlated, we compared the data distribution by fitting three models (linear, logarithmic and quadratic) and selecting the best one by the AIC (Akaike Information Criterion).

To relate the assemblages of species in a symmetric way, we used co-inertia analysis (CoIA). CoIA is a general and flexible way to couple two or more datasets, which are ordered along the axes of CoIA analysis to maximize covariance. In our case we compared two datasets, one for $\mathrm{HS}_{\mathrm{i}}$ and another for $\mathrm{H}^{\prime} \mathrm{H}_{\mathrm{i}}$ for all the 12 habitat-related breeding bird communities (Supplementary materials S2). The RV coefficient is a multivariate generalization of the Pearson correlation coefficient. This coefficient ranges between 0 and 1: the closer the coefficient to 1 , the stronger the correlations between the datasets. The strength of CoIA is that it can deal with large numbers of variables in each set and that it includes, by way of preprocessing the weight of rows and columns with the condition that the row weights must be equal in the two separate ordinations (ter Braak and Schaffers 2004). The method finds a common space onto which the objects (i.e., habitat types and their communities in this study) and variables of these datasets can be projected and compared. The ordination method used by CoIA can be the correspondence analysis or principal component analysis (PCA in our analysis). We performed a permutation test (999 in our analysis) to assess the significance of the co-structure of the data tables.

The analyses were performed using R3.0.3 software for Windows (R Core Team 2017). The alpha was set to 0.05 . 
Table 4. Scores of $\mathrm{HS}_{\text {tot }}$ (and \pm standard deviation, s.d) and $\mathrm{H}^{\prime} \mathrm{H}_{\text {tot }}$ for the 12 habitat-related bird communities. Confidence intervals $\left(5^{\text {th }}\right.$ and $95^{\text {th }}$ percentile) are also reported.

\begin{tabular}{lllclcc}
\hline & & \multicolumn{2}{c}{ confidence intervals } & & \multicolumn{2}{c}{ confidence intervals } \\
\hline $\begin{array}{c}\text { Habitat-related } \\
\text { community }\end{array}$ & $\mathrm{HS}_{\text {tot }}($ and \pm s.d. $)$ & $5^{\text {th }}$ percentile & $\begin{array}{c}95^{\text {th }} \\
\text { percentile }\end{array}$ & $\mathrm{H}^{\prime} \mathrm{H}_{\text {tot }}$ & $5^{\text {th }}$ percentile & $\begin{array}{c}95^{\text {th }} \\
\text { percentile }\end{array}$ \\
\hline Urb & $2.851( \pm 1.62)$ & 2.863 & 2.562 & 0.944 & 0.950 & 0.854 \\
Cr1 & $2.267( \pm 1.05)$ & 2.274 & 2.073 & 1.005 & 1.010 & 0.910 \\
Oli & $2.367( \pm 1.15)$ & 2.378 & 2.148 & 0.987 & 0.992 & 0.884 \\
Mo1 & $2.288( \pm 1.07)$ & 2.300 & 2.061 & 0.981 & 0.986 & 0.877 \\
Mo2 & $2.523( \pm 1.30)$ & 2.531 & 2.293 & 1.048 & 1.053 & 0.948 \\
Cr2 & $2.378( \pm 1.13)$ & 2.387 & 2.085 & 0.747 & 0.753 & 0.656 \\
Mo3 & $2.457( \pm 1.22)$ & 2.464 & 2.082 & 0.723 & 0.727 & 0.627 \\
Ree & $0.514( \pm 1.23)$ & 0.514 & 0.486 & 0.069 & 0.069 & 0.062 \\
Fo1 & $1.103( \pm 1.05)$ & 1.109 & 0.890 & 0.734 & 0.738 & 0.599 \\
Fo2 & $1.682( \pm 0.45)$ & 1.687 & 1.523 & 0.825 & 0.828 & 0.727 \\
Fo3 & $1.989( \pm 0.76)$ & 1.998 & 1.770 & 0.900 & 0.906 & 0.797 \\
Fo4 & $2.278( \pm 1.05)$ & 2.291 & 2.054 & 1.169 & 1.177 & 1.038 \\
\hline
\end{tabular}

\section{Results}

The 20 matrices, each one made of 10 point counts randomly selected, showed $\mathrm{R}$ indexes close to zero for each habitat type indicating completely random grouping (i.e., no significant difference between and within matrices) (Table 3 ).

In the 12 habitat-related bird communities we detected a total of 54 breeding species each one having specific $\mathrm{HS}_{\mathrm{i}}$ and $\mathrm{H}^{\prime} \mathrm{H}_{\mathrm{i}}$, scores (Supplementary materials S2).

At community level, the scores of the cumulative indices $\mathrm{HS}_{\text {tot }}$ and $\mathrm{H}^{\prime} \mathrm{H}_{\text {tot }}$ are reported in Table 4. Plotting these data in a Cartesian space shows a clear trend moving from reed bed community (placed at the end in the lower left; low values of both indexes) to forest communities (placed in an intermediate position along the gradient), to mosaic communities (having higher scores), to urban habitats (right end of the diagram) (Fig. 1). The best fitting model of these data resulted the quadratic model expressed by a weak hump-shaped curve (AIC = $\left.-7.94, \mathrm{R}^{2}=0.78, \mathrm{~F}_{2,9}=16.37, \mathrm{p}=0.001\right)$ when compared with logarithmic model $\left(\mathrm{AIC}=-7.53, \mathrm{R}^{2}=0.73\right)$ and linear model $\left(\mathrm{AIC}=-2.67, \mathrm{R}^{2}=0.60\right)$. Among the four forest communities a growing trend in $\mathrm{H}^{\prime} \mathrm{H}_{\text {tot }}$ and $\mathrm{HS}_{\text {tot }}$ moving from beech wood (Fo1), to Mediterranean high forest (Fo2), to coppice (Fo3), and urban park (Fo4) was observed (Fig. 1).

The CoIA analysis showed a strong and significant relationship between these two variables in each habitat type (RV coefficient $=0.992, p=0.001$ after 999 permutations). Of the 11 axes of CoIA, the first five axes (cumulative inertia) explained more than $90 \%$ of the total variation (i.e., axes from 1 to $5=91.41 \%$ of cumulative projected inertia). The first two axes explained $62.61 \%$ of the total variation (Axis $1=$ $40.36 \%$ of the variation, eigenvalue $=158.27$, covariance $=$ 12.58, correlation coefficient between $\mathrm{H}^{\prime} \mathrm{H}_{\mathrm{i}}$ and $\mathrm{HS}_{\mathrm{i}}$ scores on the Axis $1=0.9987$; Axis $2=22.25 \%$ of the variation, eigenvalue $=87.26$, covariance $=9.34$, correlation coefficient between $\mathrm{H}^{\prime} \mathrm{H}_{\mathrm{i}}$ and $\mathrm{HS}_{\mathrm{i}}$ values on the Axis $2=0.9989$ ). The normed site score plot (Fig. 2) showed the position of the 12 habitat types projected on the CoIA axes based on the correlation between the canonical weight of the $\mathrm{H}^{\prime} \mathrm{H}_{\mathrm{i}}$ and $\mathrm{HS}_{\mathrm{i}}$ values of the species. Figure 2 also shows that, based on species-specific weighted scores of $\mathrm{HS}_{\mathrm{i}}$ and $\mathrm{H}^{\prime} \mathrm{H}_{\mathrm{i}}$, these two indices discriminated different groups of habitat-related communities: (i) a first group of forest communities, where different mature woods (Fo1, Fo2, Fo4) were separated from the coppiced wood community (Fo3); (ii) a second group including communities living in less disturbed traditional habitats such as mosaics, crop lands, olive groves (Mo1, Mo2, Cr1, Oli); (iii) a third group of communities located in agricultural habitat types embedded in highly disturbed landscapes (Cr2 and Mo3). Finally, two different habitat-related communities showed an isolated placement: the highly disturbed urban habitat (Urb) and, at the opposite, the low disturbed wetland reed beds (Ree).

\section{Discussion}

Studies exploiting the concept of hemeroby are quite numerous in plant ecology but this concept has been very rarely tested in the field of animal ecology. Battisti et al. (2016) calculated the hemeroby for the bird species of the Torre Flavia marshland, a site on the coast near Rome, comparing these values with the plant communities of the marshland, obtaining a good correspondence. Extending this concept to animals, Battisti and Fanelli (2015a) calculated the hemeroby values for most common bird species of a large area of central Italy on the basis of the regional range of their distribution. These values made possible the evaluation at community level of 


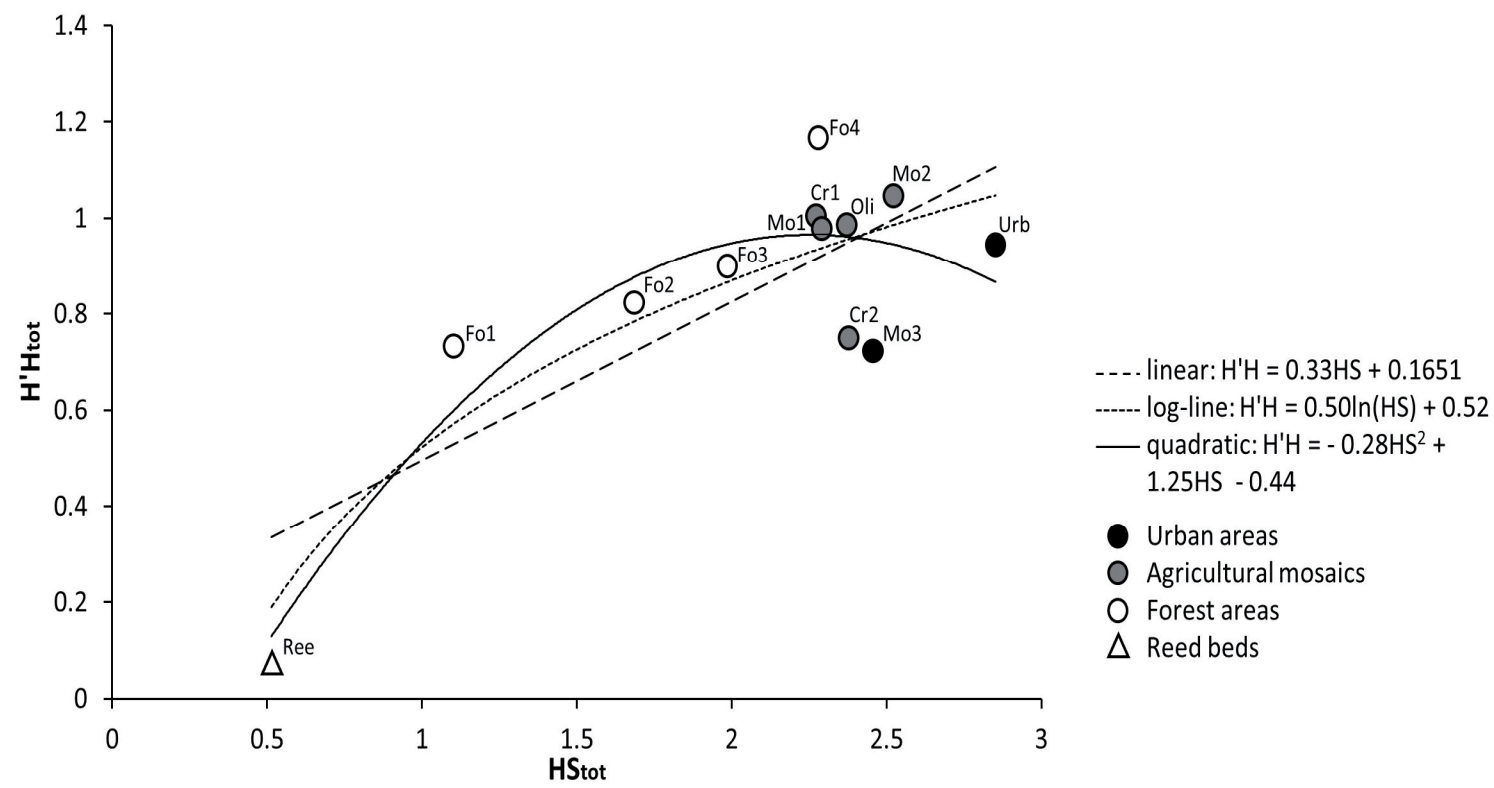

Figure 1. Relationship between $\mathrm{HS}_{\text {tot }}$ (hemeroby) and $\mathrm{H}^{\prime} \mathrm{H}_{\text {tot }}$ (hemerobiotic diversity) on the 12 avian communities. The quadratic model best described the data distribution (see Results). For habitat type description and codes, see Table 1.

Figure 2. Normed site scores plot of the 12 habitat types. This graph shows the position of the habitat types on the CoIA space obtained by the correlation between the $\mathrm{H}^{\prime} \mathrm{H}_{\mathrm{i}}$ and $\mathrm{HS}_{\mathrm{i}}$ scores of the species in each community. For habitat type description and codes, see Table 1.

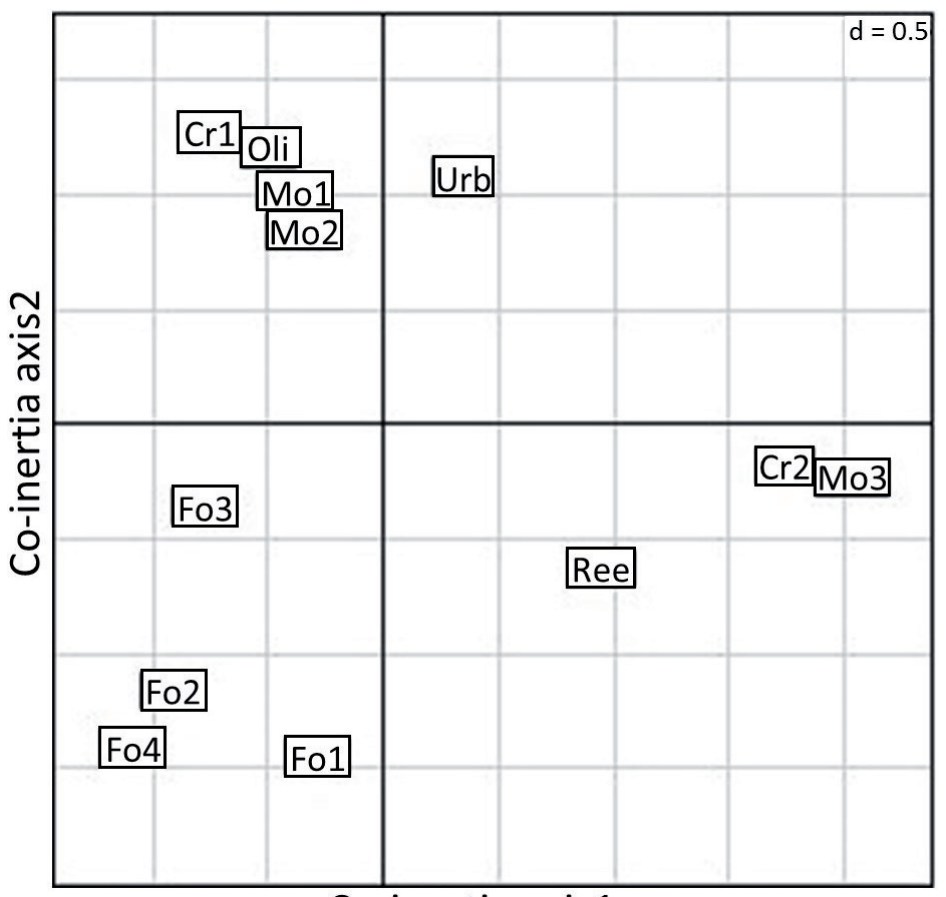

Co-inertia axis1

the hemeroby score $\left(\mathrm{HS}_{\mathrm{tot}}\right)$, a proxy for the total preference towards differently disturbed habitats, and a hemerobiotic diversity $\left(\mathrm{H}^{\prime} \mathrm{H}_{\mathrm{tot}}\right)$, a proxy for their total amount of generalism, along a rural-urban gradient.

The strong correlation between $\mathrm{H}^{\prime} \mathrm{H}_{\mathrm{i}}$ and $\mathrm{HS}_{\mathrm{i}}$ resulted from CoIA supported what we observed for total values. However, although the scores in $\mathrm{HS}_{\text {tot }}$ and $\mathrm{H}^{\prime} \mathrm{H}_{\text {tot }}$ obtained in our set of habitat-related communities appear directly correlated (i.e., increasing the total level of hemeroby in a community, increase the total level of generalism), the best fit line in the relationship between $\mathrm{HS}_{\text {tot }}$ and the $\mathrm{H}^{\prime} \mathrm{H}_{\text {tot }}$ also suggests a weak tendency for a hump-shaped pattern corroborating the evidence yet obtained at species level (intermediate generalism hypothesis; Battisti and Fanelli 2015a). At single species level, this hypothesis stated that in a generalism/disturbance comparisons $\mathrm{HH}$ values are normally distributed, indicating that generalism peaks at intermediate levels of disturbance: i.e., species linked to intermediate disturbed habitat types (intermediate HS values) may occur in a large spectrum of habitat types (high $\mathrm{HH}$ ) and thus show higher level of generalism. Conversely, species linked to higher or lower HS values (either pristine habitats or heavily disturbed habitats) 
showed lower HH values, i.e., are restricted to a narrow range of habitat types.

At community level, this tendency appears weak because the number of studies here reviewed is not high as the number of species analyzed in the previous work (12 vs. 75; Battisti and Fanelli 2015a). However, having a larger set of communities located on a wider gradient in habitat disturbance, we hypothesize that the interemediate generalism hypothesis could be corroborated also at community level, i.e., that the relationship between hemeroby and generalism could be hump-shaped with a peak in hemeroby at intermediate levels of generalism.

However, moving from communities inhabiting wetland reed beds, characterized by lowest total values in hemeroby and generalism because of largely composed by highly specialized water-related species (Báldi and Kisbenedek 1999, Paracuellos 2006, Benassi et al. 2009), we observed progressively higher scores in both the indices for forests, to open scrubland/grassland mosaics. At the extreme was located the urban habitat, characterized from the highest value of $\mathrm{HS}_{\text {tot }}$ (highest weighted hemeroby), which showed indeed a tendential decrease in hemerobiotic diversity values $\left(\mathrm{H}^{\prime} \mathrm{H}_{\text {tot }}\right)$. In particular, urban and open mosaic habitat types largely overlap in respect of the $\mathrm{HS}_{\text {tot }}$ scores, but they may be differentiated according to the level of $\mathrm{H}^{\prime} \mathrm{H}_{\text {tot }}$. This seems to show that the species of highly disturbed habitats (e.g., urban contexts) are generally more specialized due to their occurrence only in heavily anthropized contexts, whereas the species of open mosaic, exploring a number of different habitats could show a lower specialisation (lower H'H) (see Suárez-Soane et al. 2002).

An interesting aspect is represented by the fact that different forest types are clearly separated along the axis of total hemeroby and generalism. Mature, more structured forests with lower level of disturbance (beech woodlands, Fo1, and mature Mediterranean forests, Fo2) resulted less hemerobiotic $\left(\right.$ lower $\left.\mathrm{HS}_{\text {tot }}\right)$ and composed from more specialized species (lower $\mathrm{H}^{\prime} \mathrm{H}_{\mathrm{tot}}$ ) than coppiced (Fo3) and urban forests (Fo4). Also the co-inertia analysis showed that the coppiced forest (Fo3) is different from the other forest types, including the urban forest (Fo4). This result can indicate that the coppiced forest is a more disturbed habitat type when compared to other forest types, hosting a bird community of species with higher values of $\mathrm{H}^{\prime} \mathrm{H}_{\mathrm{i}}$ and $\mathrm{HS}_{\mathrm{i}}$. In this case, the urban forest (Fo4) resulted more similar to the mature forests (Fo1 and Fo2) possibly because the urban forest is an urban park characterized by a core area of mature trees, hosting disturbance-sensitive and interior species with a lower degree of generalism (lower H'H $\mathrm{H}_{\mathrm{i}}$ values; e.g., woodpeckers, Sitta europaea; Matthysen et al. 1995, Bianconi et al. 2004, Villard and Jonsson 2009).

Therefore, our results suggest that the total scores either of hemeroby $\left(\mathrm{HS}_{\mathrm{tot}}\right)$ and generalism $\left(\mathrm{H}^{\prime} \mathrm{H}_{\mathrm{tot}}\right)$ calculated for these assemblages might act as a good community-based indicators of the degree of naturalness of forest habitat types. This is an important result, since that it is sometimes difficult to differentiate forests with different level of impact (Anderson 1991, Winter 2012): Indeed, although there is a very characteristic flora of old-growth forests (e.g., Peterken 1974, Bossuyt 1999), the floristic turnover related to disturbance is generally small, and therefore plant hemeroby values can be of little use in the assessment of naturalness along gradients. Other indicators, for instance the structure of forest, the changes in cover values inside the communities and presence of dead wood can be useful, and a certain number of models have been developed (Canterbury et al. 2000, Reif and Walentowski 2008, Winter 2012, Testi et al. 2009, Redolfi De Zan et al. 2016, Rossi de Gasperis et al. 2016). Hemeroby calculated only on floristic data has been used successfully for the assessment for forest naturalness, but this effort is effective usually along broad gradients and at a large scale, whereas it seems less efficient at smaller scale and with finer detail (Grabherr et al. 1998). Probably weighted values at vegetation levels, and, in our case, the differentiation of forest-related bird communities are instead striking with a clear gradient differentiating mature from coppiced forests along a hemeroby-generalism gradient.

Regarding non-forest communities, we showed by coinertia analysis that crop-land (Cr1), olive groves (Oli), and mosaics in agricultural context (Mo1 and Mo2) are close to each other, hosting species with high degree of both indices: probably these habitat types have a high level of heterogeneity typical of agricultural mosaic landscapes implying the presence of species at medium level of generalism (Benton et al. 2003, Devictor et al. 2008b). Differently, crop-land and mosaics surrounded from an urbanized matrix ( $\mathrm{Cr} 2$ and Mo3) host a high number of highly disturbance-related species, which can explain their isolated location. Finally, two communities related to very different habitat types (urban settlements, Urb, and reed beds, Ree), appear nearby and isolated in the CoIA pattern: following our hemeroby/generalism similarity criterion, the presence of a large set of peculiar and specialized species (respectively, synanthropic and wetlandrelated species) may explain their peculiar placement.

\section{Conclusions}

Our results suggest that the hemeroby of breeding birds $\left(\mathrm{HS}_{\mathrm{tot}}\right)$, related to their level of generalism $\left(\mathrm{H}^{\prime} \mathrm{H}_{\mathrm{tot}}\right)$, may represent an useful and operational tool when studying the level of disturbance expressed from bird assemblage along habitat gradients. These two indicators here applied at higher hierarchical level (from species to community) might be used in assessment in environmental quality of specific habitat types of conservation concern or management interest (e.g., Special Areas of Conservation; Habitat 92/43/CEE). The main strength of this approach is its ease in use due to common species involved, which are easily detectable with a quick method and often better indicate the state of an ecosystem when compared to rarest ones (Gregory et al. 2003, Battisti and Fanelli 2015b, Koch et al. 2011).

Acknowledgments: We wish to thank an anonymous reviewer for their useful comments and suggestions that largely improved the first and second draft of the manuscript. 


\section{References}

Anderson, J.E. 1991. A conceptual framework for evaluating and quantifying naturalness. Conserv. Biol. 5:347-352.

Báldi, A. and Kisbenedek, T. 1999. Species-specific distribution of reed-nesting passerine birds across reed bed edges: effects of spatial scale and edge type. Acta Zool. Hung. 45:97-114.

Battisti, C., Capecchi, P. 2015. L'avifauna della Riserva naturale provinciale "Villa Borghese di Nettuno" (Italia centrale), con particolare riferimento alla composizione e struttura della comunità nidificante. Boll. Mus. Civ. St. Nat. Verona, Bot. Zool. 39:1-8.

Battisti, C. and Fanelli, G. 2011. Does human-induced heterogeneity differently affect diversity in vascular plants and breeding birds? Evidences from three Mediterranean forest patches. Rendiconti Lincei 22:25-30.

Battisti C. and Fanelli G. 2015a. Applying indicators of disturbance from plant ecology to vertebrates: The hemeroby of bird species. Ecol. Indic. 61:799-805.

Battisti, C. and Fanelli, G. 2015b. Don't think local! Scale in conservation, parochialism, dogmatic bureaucracy and the implementing of the European Directives. J. Nat. Conserv. 24:24-30.

Battisti, C., Poeta, G. and Fanelli, G. 2016. An Introduction to Disturbance Ecology. A Road Map for Wildlife Management and Conservation. Springer, Cham, Switzerland.

Belmaker, J., Sekercioglu, C.H. and Jetz, W. 2012. Global patterns of specialization and coexistence in bird assemblages. J. Biogeogr. 39:193-203.

Benassi, G., Battisti, C., Luiselli, L. and Boitani, L. 2009. Area-sensitivity of three reed bed bird species breeding in Mediterranean marshland fragments. Wetl. Ecol. Manag. 17:555-564.

Benton, T.G., Vickery, J.A. and Wilson, J.D. 2003. Farmland biodiversity: is habitat heterogeneity the key? Trends Ecol. Evol. 18:182-188.

Bianconi R., Battisti C., Zapparoli M. 2004. Pattern of richness, abundance and diversity of four interior bird species in a hilly landscape in Central Italy: a contribution to assess their sensitivity to habitat fragmentation. J. Medit. Ecol. 4:37-44.

Bibby, C.J., Burgess, N.D., Hill, D.A. and Mustoe, S.H. 2000. Bird Census Techniques, 2nd ed. Academic Press, London.

Blair, R. 2004. The effects of urban sprawl on birds at multiple levels of biological organization. Ecology and Society 9(5):2. [online] URL: http://www.ecologyandsociety.org/vo19/iss5/art2.

Bossel, H. 1999. Indicators for Sustainable Development: Theory, Method, Applications. International Institute for Sustainable Development, Winnipeg.

Bossuyt, B., Hermy, M. and Deckers, J. 1999. Migration of herbaceous plant species across ancient recent forest ecotones in central Belgium. J. Ecol. 87:517-527

Brawn, J. D., Robinson, S. K. and Thompson III, F. R. 2001. The role of disturbance in the ecology and conservation of birds. Ann. Rev. Ecol. Syst. 32:251-276.

Canterbury, G.E., Martin, T.E., Petit, D.R., Petit, L.J. and Bradford, D.F. 2000. Bird communities and habitat as ecological indicators of forest condition in regional monitoring. Conserv. Biol. 14:544-558.

Clements, J.F. 2000. Birds of the World, a Checklist. Fifth edition, Ibis, Vista, Ca.

Crooks, K.R., Suarez, A.V. and Bolger, D.T. 2004. Avian assemblages along a gradient of urbanization in a highly fragmented landscape. Biol. Conserv. 115:451-462.
Devictor, V., Julliard, R., Clavel, J., Jiguet, F., Lee, A. and Couvet, D. 2008a. Functional biotic homogenization of bird communities in disturbed landscapes. Global Ecol. Biogeogr. 17:252-261.

Devictor, V., Julliard, R. and Jiguet, F. 2008b. Distribution of specialist and generalist species along spatial gradients of habitat disturbance and fragmentation. Oikos 117:507-514.

Devictor, V. and Robert, A. 2009. Measuring community responses to large-scale disturbance in conservation biogeography. Divers. Distrib. 15:122-130.

Dornelas, M. 2010. Disturbance and change in biodiversity. Phil. Trans. R. Soc. B 365:3719-3727.

Ewers, R.M. and Didham, R.K. 2006. Confounding factors in detection of species responses to habitat fragmentation. Biol. Rev. $81: 117-142$.

Fanelli, G. and Battisti, C. 2014. Comparing disturbance-sensitivity between plants and birds: a fine-grained analysis in a suburban remnant wetland. Isr. J. Ecol. Evol. 60:11-17.

Fanelli, G. and Battisti C. 2015. Range of species occupancy, disturbance and generalism: applying hemeroby metrics to common breeding birds from a regional Atlas. Vie et Milieu - Life and Environment 65 (4):243-250.

Fanelli, G., Tescarollo, P. and Testi, A. 2005. Ecological indicators applied to urban and suburban floras. Ecol. Indic. 6:444-457.

Grabherr, G., Koch, G., Kirchmeir, H. and Reiter, K. 1998. Hemerobie österreichischer Waldökosysteme. Veröff. Des Österreichischen MAB-Programms 17:493 S.

Gregory, R.D., Noble, D., Field, R., Marchant, J., Raven, M. and Gibbons, D.W. 2003. Using birds as indicators of biodiversity. Ornis Hungarica 12:11-24.

Gregory, R. D., Noble D.G., and Custance, J. 2004. The state of play of farmland birds: population trends and conservation status of lowland farmland birds in the United Kingdom. Ibis 146 (s2):113.

Henle, K., Davies, K.F., Kleyer, M., Margules, C. and Settele, J. 2004. Predictors of species sensitivity to fragmentation. Biodiv. Conserv. 13:207-251

Hill, M.O., Roy, D.B. and Thompson, K. 2002. Hemeroby, urbanity and ruderality: bioindicators of disturbance and human impact. J. Appl. Ecol. 39:708-720.

Katayama, N., Amano, T., Naoe, S., Komatsu, I., Takagawa, S., Sato, N., Ueta, M. and Miyashita, T. 2014. Landscape heterogeneity-biodiversity relationship: effect of range size. PLOS One 9:e93359.

Koch, A.J., Drever, M.C. and Martin, K. 2011. The efficacy of common species as indicators: avian responses to disturbance in British Columbia. Biodiv. Conserv. 20:3555-3575.

Kowarik, I. 1988. Zummenschlichen Einfluss auf Flora und Vegetation: Theoretische Konzepte und ein Quantifizierungsansatz am Beispiel von Berlin (West). Landschaftsentwicklung und Umweltforschung, Schriftenreihe des Fachbereichs Landschaftsentwicklung der TU Berlin Vol. 56:241.

Julliard, R., Clavel, J., Devictor, V., Jiguet, F. and Couvet, D. 2006. Spatial segregation of specialists and generalists in bird communities. Ecol. Lett. 9:1237-1244.

Lack, P.C. 1986. The Atlas of Wintering Birds in Britain and Ireland. TAD Poyser, London.

Malavasi, R., Battisti, C. and Carpaneto, G.M. 2009. Seasonal bird assemblages in a Mediterranean patchy wetland: corroborating the intermediate disturbance hypothesis. Pol. J. Ecol. 57:171179. 
Marzluff, J.M., Bowman, R. and Donnelly, R. (eds.) 2001. Avian Ecology and Conservation in an Urbanizing World. Kluwer Academic Publishers, New York.

Matthysen, E., Lens, L., Van Dongen, S., Verheyen, G.R., Wauters, L.A., Adriaensen, F. and Dhondt, A.A. 1995. Diverse effects of forest fragmentation on a number of animal species. Belg. $J$. Zool. 125:175-183.

Morelli, F., Benedetti, Y., Ibáñez Álamo, J. D., Jokimäki, J., Mänd, R., Tryjanowski, P. and Møller, A.P. 2016. Evidence of evolutionary homogenization of bird communities in urban environments across Europe. Glob. Ecol. Biogeogr. 25 :1284-1293.

Mouillot, D., Graham, N.A.J., Villéger, S. and Mason, N.W.H. 2013. A functional approach reveals community responses to disturbances. Trends Ecol. Evol. 28:167-177.

Paracuellos, M. 2006. Relationship of song bird occupation with habitat configuration and bird abundance in patchy reed beds. Ardea 94:87-98

Peterken, G.F. 1974. A method for assessing woodland flora for conservation using indicator species. Biol. Conserv. 6:239- 247.

R Core Team . 2017. R: A language and environment for statistical computing. R Foundation for Statistical Computing, Vienna, Austria.

Redolfi De Zan, L., Rossi de Gasperis S., Fiore L., Battisti, C. and Carpaneto, G.M. 2016. The importance of dead wood for holenesting birds: a two years study in three beech forests of central Italy. Isr. J. Ecol. Evol. DOI: 10.1080/15659801.2016.1191168.

Reif, A. and Walentowski, H. 2008 The assessment of naturalness and its role for nature conservation and forestry in Europe. Waldökologie, Landschaftsforschung und Naturschutz 6:63-76.

Reif, J., Marhoul, P. and Koptík, J. 2013. Bird communities in habitats along a successional gradient: Divergent patterns of species richness, specialization and threat. Basic Appl. Ecol. 14:423-431.

Rossi de Gasperis, S., Redolfi De Zan, L., Battisti, C., Reichegger, I. and Carpaneto, G.M. 2016. Distribution and abundance of holenesting birds in Mediterranean forests: impact of past management patterns on habitat preference. Ornis Fenn. 93:100-110.

Schleupner, C. and Schenider, U.A. 2013. Allocation of European wetland restoration options for systematic conservation planning. Land Use Policy 30:604-614.

Sharrock, J.T.R. 1976. The Atlas of Breeding Birds in Britain and Ireland. T. and A.D. Poyser, London.

Steinhardt, U., Herzog, F., Lausch, A., Miller, E. and Lehmann, S. 1999. Hemeroby index for landscape monitoring and evaluation. In: Pykh, Y.A. et al. (eds.), Environmental Indices - System Analysis Approach. EOLSS Publishing, Oxford, pp. 237-254.
Sousa, W.P. 1984. The role of disturbance in natural communities. Ann. Rev. Ecol. Syst. 15:353-391.

Suárez-Soane, S., Osborne, P.E., Alonso, J.C. 2002. Large-scale habitat selection by agricultural steppe birds in Spain: identifying species-habitat responses using generalized additive models. $J$. Appl. Ecol. 39:755-771.

Taffon, D. and Battisti, C. 2005. Breeding bird communities and ecotope niche breadth of the species in a heterogeneous landscape of Central Italy. Riv. ital. Ornitol., Research in Ornitology 75:129-139.

ter Braak, C.J.F. and Barendregt, L.G. 1986. Weighted averaging of species indicator values: its efficiency in environmental calibration. Math. Biosci. 78:57-72.

ter Braak, C. J. F. and Schaffers, A.P. 2004. Co-correspondence analysis: a new ordination method to relate two community compositions. Ecology 85:834-846.

Testi, A., Guidotti, S., Bisceglie, S. and Fanelli, G. 2009. Detecting river environmental quality through plant and macroinvertebrate indicators in the Aniene River (Central Italy). Aquat. Ecol. 43:477-486

Villard, M.-A. 1998. On forest-interior species, edge avoidance, area sensitivity, and dogma in avian conservation. Auk 115:801-805.

Villard, M.-A. and Jonsson, B.G. 2009. Setting Conservation Targets for Managed Forest Landscapes. Cambridge University Press, Cambridge.

Vuerich, V., Bologna, M.A. and Battisti, C. 2006. Comunità ornitiche nidificanti in tre tipologie vegetazionali lungo un gradiente altitudinale nei monti Simbruini (Lazio, Appennini centrali) (Aves). Aldrovandia 2:49-53.

Wiens, J.A. 1989. The Ecology of Bird Communities. Vols. 1-2. Cambridge studies in ecology, Cambridge University Press, Cambridge, UK.

Winter, S. 2012. Forest naturalness assessment as a component of biodiversity monitoring and conservation management. Forestry 85:293-304.

Received November 15, 2017

Revised December 22, 2017

Accepted December 29, 2017

\section{Supplemetary material}

Appendix S1. Relative frequencies of the species for each habitat-related community.

Appendix S2. $\mathrm{HS}_{\mathrm{i}}$ and $\mathrm{H}^{\prime} \mathrm{H}_{\mathrm{i}}$ scores at regional level and for each habitat-related community. 